\title{
Emerging environmental stressors and oxidative pathways in marine organisms: Current knowledge on regulation mechanisms and functional effects
}

\author{
Maura BENEDETTI*; Maria Elisa GiUliani; Marica MEZZELANI; Alessandro NARDi; Lucia PITTURA; Stefania GORBI; \\ FRANCESCO REGOLI \\ Dipartimento di Scienze della Vita e dell'Ambiente, Università Politecnica delle Marche, Ancona, 60131, Italy
}

Key words: Antioxidant, Pharmaceuticals, Microplastics/Nanoplastics, Ocean acidification, Thermal stress

\begin{abstract}
Oxidative stress is a critical condition derived from the imbalance between the generation of reactive oxygen species and the sophisticated network of antioxidant mechanisms. Several pollutants and environmental factors can affect this system through connected mechanisms, indirect relationships, and cascade effects from pre-transcriptional to catalytic level, by either enhancing intracellular ROS formation or impairing antioxidant defenses. This review summarizes the current knowledge on the pro-oxidant challenges from emerging environmental stressors threatening marine organisms, such as pharmaceuticals, microplastics and climate-related ocean changes. Emphasis will be placed on oxidative pathways, including signaling proteins and transcription factors involved in regulation of antioxidant responsiveness. Mechanistic insights and lack of knowledge will be pointed out by presenting single and combined effects of multiple stressors, unravelling questions to be addressed by future research in marine ecotoxicology.
\end{abstract}

\section{Abbreviations:}

(AP1): $\quad$ Activator protein 1

(APIs): $\quad$ Active Pharmaceutical Ingredients

(ATP): adenosine triphosphate

(CAT): Catalase

(CBZ): Carbamazepine

(CYP450): Cytochrome P450

(DIC): Diclofenac

(ERK): extracellular signal-regulated kinase

(FLU): $\quad$ Fluoxetine

(GCLC): Glutamate-Cysteine Ligase Catalytic Subunit

(GPx): Glutathione peroxidases

(GR): Glutathione reductase

(GSH): Glutathione

(GST): $\quad$ Glutathione S-transferases

(JNK): c-Jun N-terminal kinase

(Keap1): $\quad$ Kelch Like ECH Associated Protein 1

(MAPK): Mitogen-activated protein kinases

(MPs): Microplastics

(NADPH): Nicotinamide adenine dinucleotide phosphate

$\begin{array}{ll}\text { (NPs): } & \text { Nanoplastics } \\ \text { (Nrf2): } & \text { NF-E2-related factor } 2 \\ \text { (NF-kB): } & \text { Nuclear factor kappa B } \\ \text { (NSAIDs): } & \text { Non-Steroidal Anti-Inflammatory drug } \\ \text { (PA): } & \text { polyamide } \\ \text { (PAH): } & \text { Polycyclic aromatic hydrocarbon } \\ \text { (PAR): } & \text { paroxetine } \\ \text { (PE): } & \text { polyethylene } \\ \text { (PET): } & \text { polyethylene terephthalate } \\ \text { (PLHC-1): } & \text { Poeciliopsis lucida hepatocellular carcinoma } \\ \text { (PP): } & \text { polypropylene } \\ \text { (PS): } & \text { polystyrene } \\ \text { (PVC): } & \text { polyvinylchloride } \\ \text { (RCS): } & \text { reactive carbonate species } \\ \text { (RNS): } & \text { Reactive nitrogen species } \\ \text { (ROS): } & \text { Reactive oxygen species } \\ \text { (SAF-1): } & \text { Sparus aurata Fibroblast-1 } \\ \text { (SOD): } & \text { Superoxide dismutase } \\ \text { (SSRIs): } & \text { Selective Serotonin Reuptake Inhibitors } \\ \text { (Trx2): } & \text { Thioredoxin } 2 \\ \text { (TrxR): } & \text { Thioredoxin reductases }\end{array}$

\footnotetext{
*Address correspondence to: Maura Benedetti, m.benedetti@univpm.it Received: 15 May 2021; Accepted: 15 June 2021
} cited. 


\section{Introduction}

The maintenance of redox status is crucial for aerobic organisms, which are exposed to intracellular fluctuations of ROS, derived either from their own metabolism or from the external stimuli. Main sources of ROS formation include electron transport chain of mitochondria, peroxisomal and lysosomal functions, Fenton's and Haber-Weiss's reactions, and activities of specific oxido-reductase enzymes like monoamine oxidase, NADPH oxidase, xanthine oxidoreductase, arachidonic acid and cytochrome $\mathrm{P} 450$ oxidase, as well as inactivation of antioxidant enzymes and depletion of free radical scavengers (Regoli and Giuliani, 2014; Halliwell and Gutteridge, 2015). ROS have detrimental effects on cellular molecules and structures, resulting in lipid peroxidation, protein oxidation, DNA damage and unbalance of intracellular redox status. On the other side, ROS also act as signaling molecules, which trigger cytoprotective and antioxidant responses to protect the cellular components from oxidative damage and minimize their damaging effects (Halliwell and Gutteridge, 2015; Sachdev et al., 2021). Antioxidants include enzymes and nonenzymatic molecules that neutralize ROS and other oxidant molecules (Tab. 1).

The generation of ROS is a mechanism common to many environmental contaminants (e.g. trace metals, polycyclic aromatic hydrocarbons, polychlorinated biphenyls, halogenated compounds, dioxins) that, in addition, can also inhibit the proper functioning of antioxidant system (Benedetti et al., 2015). In this respect, investigations on oxidative metabolism are largely used to examine the health status of marine organisms, and their susceptibility toward environmental conditions (Benedetti et al., 2015). Few information is available on oxidative effects of emerging stressors in the marine environment, which are attracting great concern in the scientific community. Among these, Active Pharmaceutical Ingredient, microplastics/nanoplastics and $\mathrm{CO}_{2}$-related changes (ocean warming and acidification) have a prevalent role.

The increasing occurrence of APIs in marine environment is strictly related to the development of the global pharmaceutical market and future projections suggest this increment will continue given the human population aging and growth (IQVIA, 2019). Despite being characterized by different environmental sources and distribution pathways, wastewater treatment plants have been identified as a major route for APIs release in aquatic systems (Ojemaye and Petrik, 2019). Moreover, the numerous uses of plastic and its low degradation rates have led to the accumulation of various sizes of plastic in the marine environment (Sorensen and Jovanović, 2021). The release into the sea occurs through a variety of pathways, that include deliberate or accidental direct inputs from landand-sea-based sources and indirect inputs from land via rivers, drainage, sewage systems, atmosphere (UNEP, 2016). Nonetheless, APIs and plastics are released in oceans that are facing deep physical and chemical changes driven by the continuous emissions of anthropogenic $\mathrm{CO}_{2}$ in the atmosphere: since the beginning of the industrial revolution, oceans have warmed by $0.7^{\circ} \mathrm{C}$ and seawater $\mathrm{pH}$ decreased of 0.1 units on a global scale, due to the absorption of almost $30 \%$ of anthropogenic $\mathrm{CO}_{2}$ (IPCC, 2013); during this century, these changes are projected to continue and intensify.

TABLE 1

Function of the main non-enzymatic and enzymatic antioxidants

\begin{tabular}{|c|c|}
\hline \multicolumn{2}{|r|}{ Non-enzymatic antioxidants } \\
\hline Reduced glutathione & $\begin{array}{l}\text { Cytosolic scavenging of } \mathrm{ROS}\left({ }^{1} \mathrm{O}_{2}, \mathrm{O}_{2^{-}}, \mathrm{HO} \cdot\right) \text { and reactive nitrogen species; Cofactor of glutathione- } \\
\text { dependent antioxidant enzymes }\end{array}$ \\
\hline Ascorbic acid, vit. C & Cytosolic scavenging of $\mathrm{ROS}\left(\mathrm{H}_{2} \mathrm{O}_{2}, \mathrm{O}_{2^{-}}, \mathrm{HO} \cdot\right.$, lipid peroxides $)$ \\
\hline $\begin{array}{l}\text { a-Tocopherol, vit. E } \\
\text { Carotenoids }\end{array}$ & Membrane-bound scavenging of $\operatorname{ROS}\left({ }^{1} \mathrm{O}_{2}\right.$, peroxides $)$, protection of cell membrane from lipid peroxidation \\
\hline \multicolumn{2}{|r|}{ Antioxidant and antioxidant-related enzymes } \\
\hline Superoxide dismutase & Conversion of superoxide anion $\left(\mathrm{O}_{2^{-}}\right)$to hydrogen peroxide $\left(\mathrm{H}_{2} \mathrm{O}_{2}\right)$ \\
\hline Catalase & Reduction of $\mathrm{H}_{2} \mathrm{O}_{2}$ to $\mathrm{H}_{2} \mathrm{O}$ \\
\hline Glutathione peroxidases & Reduction of $\mathrm{H}_{2} \mathrm{O}_{2}$ and lipid peroxides \\
\hline Peroxiredoxins & Reduction of $\mathrm{H}_{2} \mathrm{O}_{2}$, lipid peroxides and peroxynitrite \\
\hline Thioredoxin & Reduction of oxidized cysteine residues \\
\hline Thioredoxin reductase & Regeneration of reduced thioredoxin \\
\hline Glutathione reductase & Reduction of oxidized glutathione (GSSG) to reduced form (GSH) \\
\hline Glutathione S-transferases & Conjugation of GSH to organic chemicals, reduction of lipid peroxides \\
\hline $\begin{array}{l}\mathrm{NAD}(\mathrm{P}) \mathrm{H} \text { :quinone } \\
\text { oxidoreductase }\end{array}$ & Reduction of quinones \\
\hline Heme oxygenase & Degradation of heme, reduction of $\mathrm{O}_{2-}$ and other ROS \\
\hline Glutamate cysteine ligase & First step of glutathione synthesis \\
\hline Glutathione synthetase & Second step of glutathione synthesis \\
\hline
\end{tabular}


Despite the subtle occurrence of these emerging stressors, they impact the environment on a global scale, modulating, alone or interacting with other stressors, several biological processes. This review summarizes the current knowledge on the oxidative effects of such new challenges in marine organisms, with particular focus on signaling pathways, regulation mechanisms and interactions between different stressors.

\section{Redox Metabolism Modulation by Residues of Active Pharmaceutical Ingredients}

The widespread occurrence of APIs in marine and coastal areas represents a serious environmental issue due to the potential long-term deleterious consequences on non-target species (Almeida et al., 2020; Mezzelani et al., 2018a; Shi et al., 2019; Zhang et al., 2020). These heterogenous chemicals ( $\sim 4000$ compounds) are specifically designed to be active on living cells at very low concentrations. Since biological targets of APIs (e.g., transporters, receptors or enzymes) are evolutionarily and functionally conserved across the animal kingdom, marine organisms are exposed to the risk of these new typology of environmental stressors (Almeida et al., 2020; Zhang et al., 2020). Antibiotics, synthetic steroids, antinflammatories, antidepressants, antiepileptics, cardiovascular and lipid regulating agents are considered as the most environmentally relevant APIs. Indeed, field investigations have documented their ubiquitous presence in water column, sediments and also in tissues of marine species (Martínez-Morcillo et al., 2020; Mezzelani et al., 2020; Moreno-González et al., 2016; Ojemaye and Petrik, 2019; Wolecki et al., 2019). Laboratory experiments contributed to demonstrate their role as promoters of molecular and biochemical changes, which might finally affect organismal physiological health status (Almeida et al., 2020; Bebianno and Gonzalez-Rey, 2015; Kovalakova et al., 2020; Mezzelani et al., 2018a,b; Zhang et al., 2020). APIs can act as enhancers of ROS production through the direct induction of the biotransformation pathway of CYP450, involved in the oxidative metabolism of numerous endogenous and exogenous compounds including several typologies of pharmaceuticals (Burkina et al., 2015; Mezzelani et al., 2018a,b; 2021). Under basal condition the ROS are generated in situ when CYP450 reacts with the substrate. However, excessive ROS production during induction results in uncoupling of the CYP450 cycle, leading to the increase of oxidative pressure (Ghosh et al., 2015). The exposure of liver slices of Atlantic cod (Gadus morhua, Linnaeus, 1758) to the synthetic steroid 17 a-ethinylestradiol EE2 enhanced cypla gene transcription (reviewed by Burkina et al., 2015), while in vitro studies on fish PLHC-1 cells exposed to the SSRIs, FLU, PAR and fluvoxamine revealed the increase of CYP450 activity demonstrating its responsiveness also at the catalytic level (Burkina et al., 2015); similarly, more elevated CYP450 activity was measured in hepatic microsomes of Dicentrarchus labrax (Linnaeus, 1758) exposed to the NSAIDs DIC (Burkina et al., 2015). Noteworthy, although the CYP450 biotransformation metabolism in marine invertebrates still needs to be fully elucidated, transcriptional changes of phase I-related genes were observed in bivalves
Mytilus galloprovincialis (Lamarck, 1819) and Ruditapes philippinarum (Adams \& Reeve, 1850) exposed to environmental levels of NSAIDs (cyp1a) and to the antiepileptic CBZ (cyp4f8, cyp3a2, cyp3a29) (Mezzelani et al., 2018a,b; 2021). The hypothesis that APIs can unbalance organismal redox homeostasis was further corroborated by a wide array of cellular damages measured in marine invertebrates: exposure to NSAIDs, SSRIs, CBZ and cardiovascular compounds was reflected by the significant increase of peroxidation products like lipofuscin and malondialdehyde in digestive gland of $M$. galloprovincialis, R. philippinarum, Scrobicularia plana (da Costa, 1778) and Venerupis decussata (Linnaeus, 1758) (Almeida et al., 2020; Franzellitti et al., 2014; Freitas et al., 2016; Hampel et al., 2017, Mezzelani et al., 2018a, 2021; Munari et al., 2014). Oxidative stress and ROS production lead to the activation of several signaling pathways involved in cell protection. In this respect, Nrf2-Keap1 modulates cytoprotective responses to oxidative stress, regulating the synthesis of antioxidant defenses to minimize oxidative damages (Espinosa-Diez et al., 2015). Although detailed mechanistic studies in marine species are limited, various investigations demonstrate the activation of Nrf2-Keap1 pathway following APIs exposure (Almeida et al., 2020; Bebianno and Gonzalez-Rey, 2015; Mezzelani et al., 2018a,b; Ruiz et al., 2020; Wang et al., 2020a). In the fish species Mugilogobius abei (Jordan \& Snyder, 1901), the widely used NSAIDs aspirin, caused a transient downregulation of Nrf2-Keap1-related genes expression (nrf2, keap1, gclc, gst, sod, cat, trx2, and trxr), followed by their induction throughout 7 days-exposure; at catalytic functional level a significant enhancement of related enzymatic activities (GPx, GST, SOD, CAT) and GSH levels were paralleled to the reduction of lipid peroxidation products (Wang et al., 2020a). Conversely, limited variations in $n r f 2$, sod and cat gene expression were observed in Sparus aurata (Linnaeus, 1758) cell line (SAF-1) exposed to CBZ (Ruiz et al., 2020), although the complex relationships between transcriptional and catalytic levels of antioxidant defenses do not allow to exclude the modulation of such cytoprotective responses at functional level (Regoli and Giuliani, 2014). In this respect, variations of antioxidant enzymes were often measured in response to APIs, highlighting species-specific, dose and compound-dependent trends (Almeida et al., 2020; Bebianno and Gonzalez-Rey, 2015; Mezzelani et al., 2018a,b). Adults of S. aurata exposed to the antibiotic erythromycin, showed inhibited activities of GPx and induction of GR (Rodrigues et al., 2019), while bivalve $S$. plana and the polychaete Diopatra neapolitana (Delle Chiaje, 1841) exhibited significant modulation of SOD, CAT and GST activity in response to CBZ (Freitas et al., 2016). Induction of SOD, CAT, GST was reported in mussels M. galloprovincialis exposed to the antinflammatory DIC (Almeida et al., 2020; Bebianno and Gonzalez-Rey, 2015), while various bivalves species (M. galloprovincialis, Perna perna, Linnaeus, 1758 and $R$. philippinarum) highlighted biphasic variations of SOD, CAT, GR and GPx and the induction of GST in response to the antidepressant FLU (reviewed by Mezzelani et al., 2018a). Among the large number of pathways regulating the perturbation of redox homeostasis (Fig. 1), the cooperation between NF-kB, AP1 


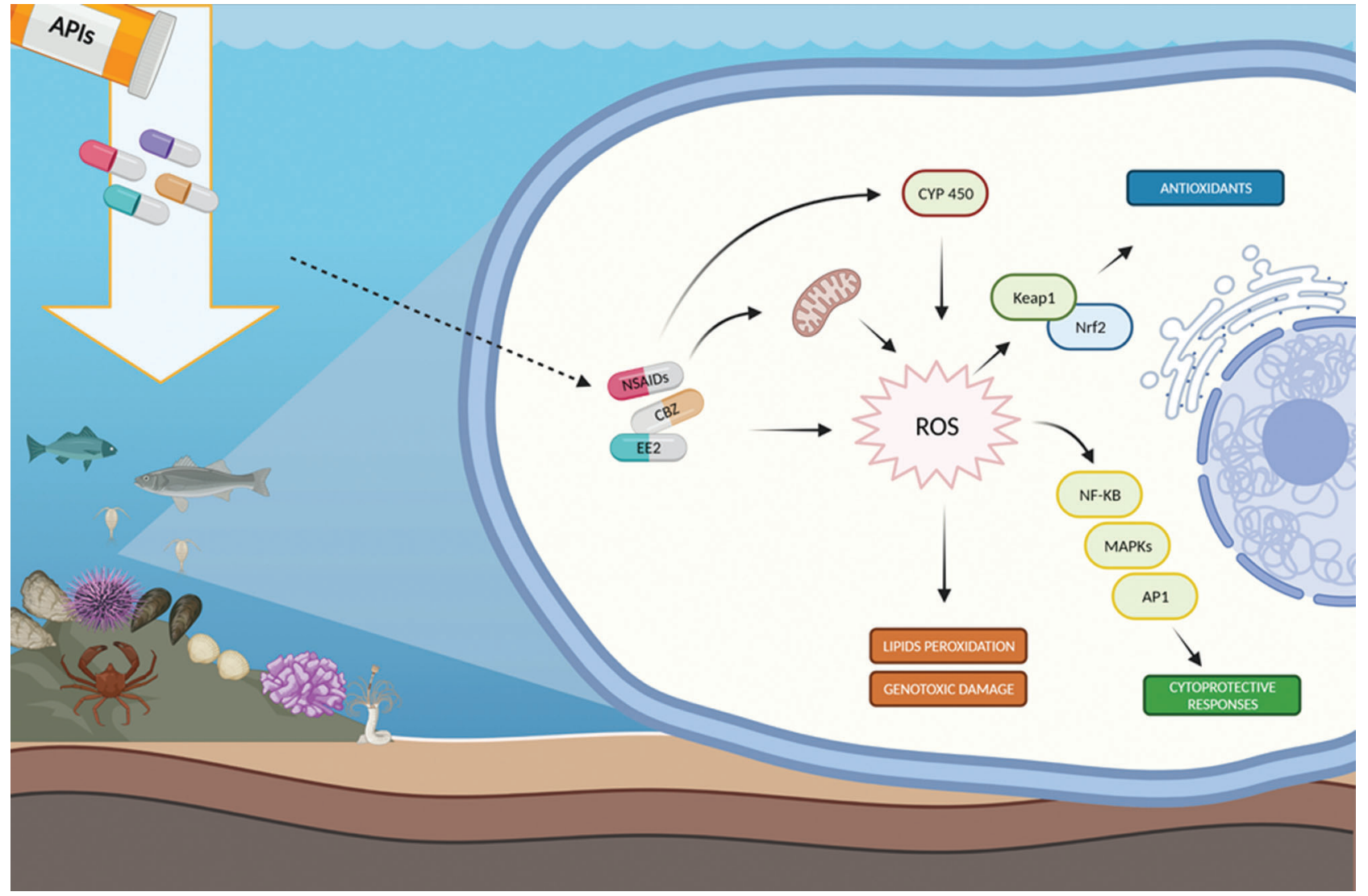

FIGURE 1. Main APIs-mediated ROS formation and scavenging pathways.

and MAPK cascade was shown to be an effective early cytoprotective response to oxidative stress (Espinosa-Diez et al., 2015). Transcriptional responses revealed enhanced mRNA levels of $n f-k b$ gene in Mytilus spp. treated with environmentally realistic concentrations of various NSAIDs, while NF-kB pathways was significantly suppressed in the bivalve Tegillarca granosa (Linnaeus, 1758) exposed to the antidepressant FLU (Shi et al., 2019; Mezzelani et al., 2018a).

\section{Microplastics/Nanoplastics and Oxidative Stress in Marine Organisms}

Over the last decade, field studies showed the constant presence of MPs in superficial seawater, along water column, in sediments, beaches and organisms worldwide (Cole et al., 2011). MPs include any synthetic solid particle or polymeric matrix, consisting of items ranging from $1 \mu \mathrm{m}$ to $5 \mathrm{~mm}$ that are manufactured to be of such microscopic dimensions, or deriving from the weathering and fragmentation of larger plastics (Bessa et al., 2019). With the advent of modern analytical techniques and detection methods, most recent studies have observed and reported plastic debris to the nanoscale (Alimba and Faggio, 2019). MPs/NPs in the oceans exist in a variety of dimensions, shapes (e.g., fragments, films, sphere, fibers), colors and polymers with different density, being PE, PS, PVC, PP, PET and PA the most frequently found (Paul-Pont et al., 2018). MPs/NPs affect all marine taxa and life stages, and observed interactions can occur via adhesion, absorption, ventilation and specially ingestion, that lead to accumulation and translocation within tissues and cells (Lusher, 2015). From an ecotoxicological perspective, MPs have the peculiar characteristic to combine a physical stress with a chemical challenge (Pittura et al., 2018). The chemical impact is mostly related to additives present in the plastic from manufacturing, as well as, to the environmental contaminants which can be adsorbed by the hydrophobic nature and high surface-to-volume ratio of MPs/NPs (Atugoda et al., 2021). Pollutant-plastic interaction depends on properties of both MPs/NPs and chemical contaminants and can be modulated by the surrounding environmental conditions of $\mathrm{pH}$, salinity and temperature (Menéndez-Pedriza and Jaumot, 2020). There is an active debate regarding the relevance of adsorption of pollutants on MPs/NPs and their possible transfer to marine organisms due to the variability of experimental results (Elizalde-Velázquez et al., 2020).

Although the ecotoxicological effects of MPs/NPs are complex to be elucidated, several studies suggested oxidative stress as an important mechanism underneath microplastics toxicity (Hu and Palić, 2020). The first evidence of disturbance in redox homeostasis was the increase of intracellular ROS levels observed in rotifers (Brachionus koreanus, Hwang, Dahms, Park \& Lee, 2013) (Jeong et al., 2016), crustaceans (Tigriopus japonicus, Mori, 1938 and Artemia salina, Linnaeus, 1758) (Choi et al., 2020; Suman et al., 2020), bivalves (Mytilus spp. and T. granosa) (Paul-Pont et al., 2016; Shi et al., 2020), and fishes (Oryzias melastigma, McClelland, 1839) (Kang et al., 2021) exposed to commercial PS-spheres, and in the sea urchin Paracentrotus lividus (Lamarck, 1816) exposed via diet to PET-MPs of irregular shape and size (Parolini et al., 2020). Given the evidence that MPs/NPs can pose an oxidative challenge to marine organisms, main mechanisms can be supposed (Fig. 2). 


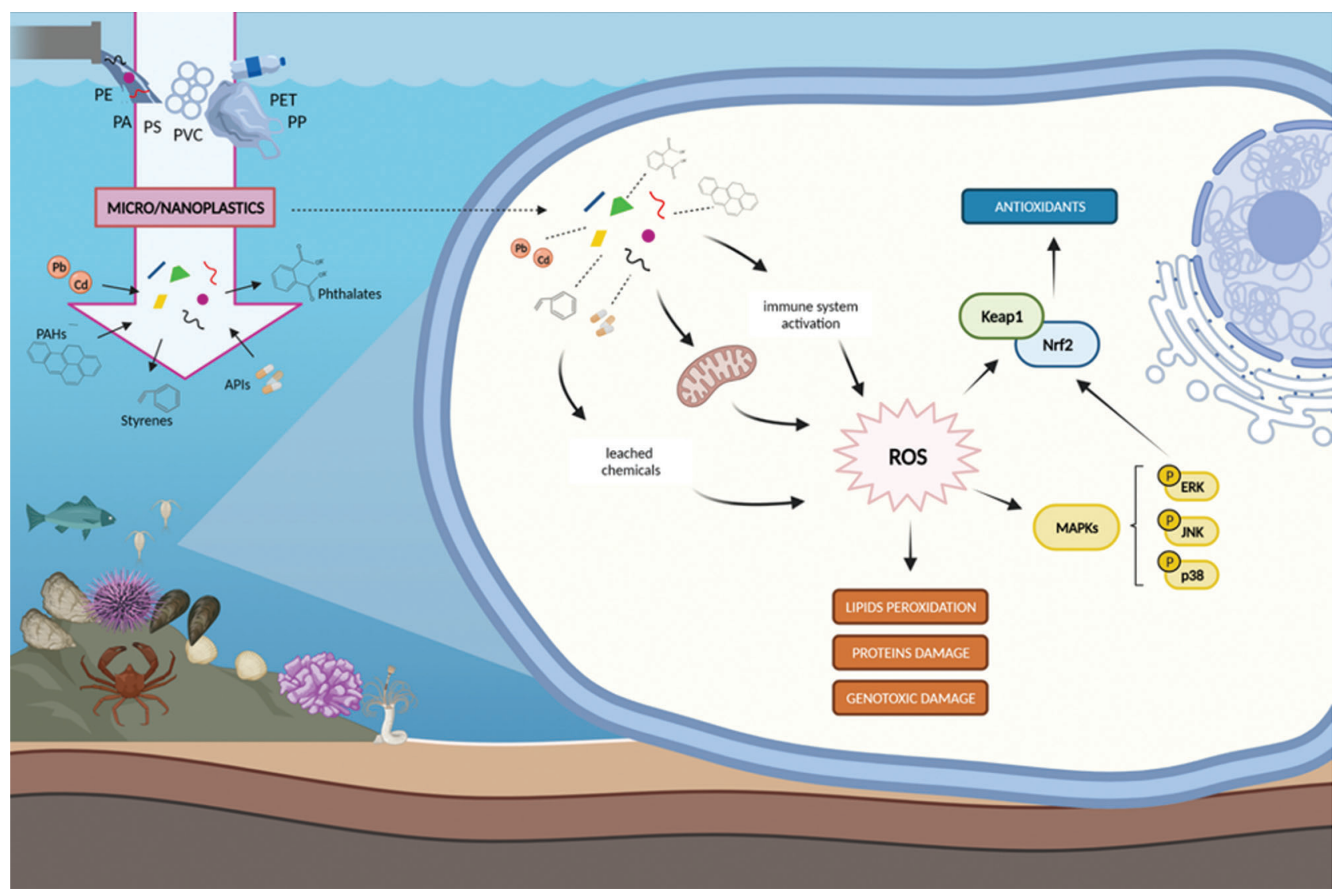

FIGURE 2. Main MPs- and NPs-mediated ROS formation and scavenging pathways.

Similar to other environmental stressors, MPs/NPs can trigger ROS production through damage to mitochondria (Yang et al., 2020), or increasing responses of the immune system during attempts of the cell to neutralize potentially infectious foreign particles (Hu and Palić, 2020; Pittura et al., 2018; Tang et al., 2018, 2020; S1kdokur et al., 2020). In addition, chemical additives leaching from plastics can further contribute to ROS formation (Hu and Palić, 2020; Yang et al., 2020). Oxidative challenge of MPs/NPs exposure was extensively supported by significant changes in antioxidant defenses (i.e., CAT, SOD, GST, GPx and GSH) both at catalytic and transcriptional level and by the onset of oxidative damages to lipids, proteins and DNA (reviewed in Trestrail et al., 2020, Kim et al., 2021, Gonçalves and Bebianno, 2021), that was even observed after exposures to environmentally realistic concentrations of MPs (Hariharan et al., 2021) and persistent also after a period of depuration (Hariharan et al., 2021; Capó et al., 2021). These effects suggest that MPs/NPs, as other pro-oxidant stimuli, can activate expression of antioxidant genes via the Nrf2dependent mechanism. The up-regulation of $n r f 2$ was measured in the head-kidney leucocytes isolated from the gilthead seabream S. aurata after exposure to PE- or PVCMPs (Espinosa et al., 2018). Since no responses of antioxidant system occurred at biochemical level, the authors hypothesized a limited oxidative challenge on Nrf2 of seabream. In the copepod Paracyclopina nana (Smirnov, 1935) a positive correlation was observed between intracellular ROS generation and phosphorylation of ERK and p38 kinase after the exposure to PS-microbeads, supporting a defense mechanism against microplasticinduced oxidative stress via the MAPK/Nrf2 pathway (Jeong et al., 2017). An increased phosphorylation of kinases, in particular p38 and JNK, after exposure to PS-microbeads was also shown in the monogonont rotifer B. koreanus, along with the induction of antioxidant enzymes, further confirming that MAPK-activating proteins are involved in signal transduction modulating the oxidative stress response (Jeong et al., 2016). In both P. nana and B. koreanus, the activation of MAPK pathway was influenced by the particle size, and the nanosized PS-beads caused higher phosphorylation of p38 MAPKs when compared to $6 \mu \mathrm{m}$ particles (Hu and Palić, 2020). The transcriptomic signal of JNK pathway was activated also in the scleractinian coral Pocillopora damicornis (Linnaeus, 1758), along with increased activities of CAT and SOD enzymes, in response to acute exposure to elevated concentrations of $1 \mu \mathrm{m}$ PSMPs (Tang et al., 2018). Based on the limited available information, MAPKs pathways might play a synergistic role with Nrf2-Keap1 in the response to oxidative stress induced by MPs/NPs in marine organisms.

\section{Ocean Changes as Sources of Oxidative Imbalance}

Ongoing ocean changes, caused by the increasing anthropogenic $\mathrm{CO}_{2}$ emissions, can represent a source of oxidative imbalance for marine organisms (Fig. 3). As alteration of environmental characteristics reaches or even exceeds the limits of homeostatic response, a number of cellular processes can reflect organisms stress-response 


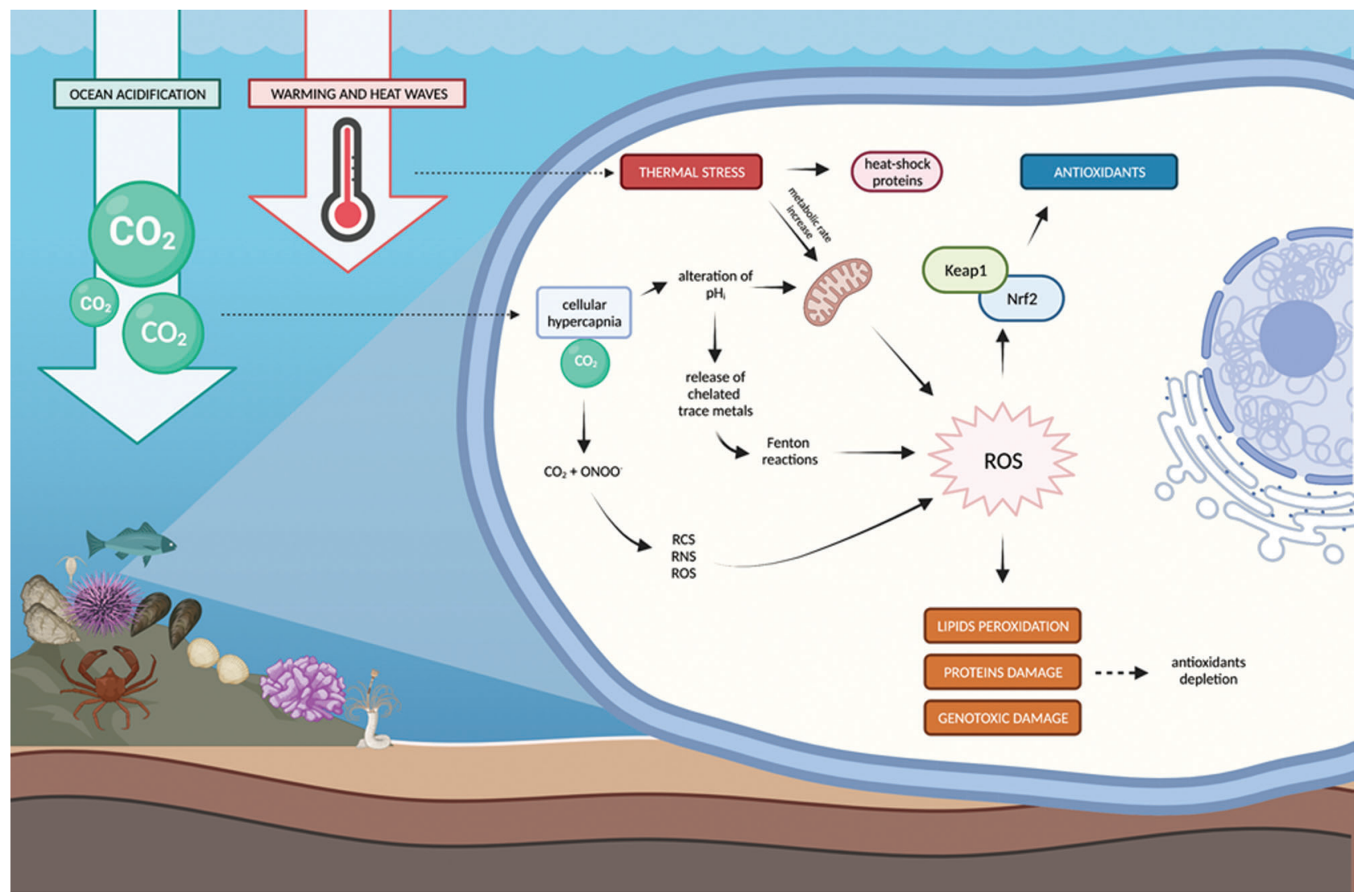

FIGURE 3. Main temperature- and $\mathrm{pH} / \mathrm{CO}_{2}$-mediated $\mathrm{ROS}$ formation and scavenging pathways.

(Tomanek, 2015). Detailing the extensive network of relationships between environmental changes, oxidative stress and individual components of the antioxidant network is beyond the scope of this review. However, the current trends of ocean warming and the frequent occurrence of extreme-temperature events (marine heatwaves) are certainly oxidative challenges for marine species. Thermal stress can directly boost the production of ROS at cellular level through increased metabolic rate and progressive mitochondrial uncoupling (Pörtner et al., 1999; Thoral et al., 2021): a positive relationship between temperature and ROS production has been demonstrated in either isolated mitochondria or in vivo studies on marine invertebrates and vertebrates (Abele et al., 2002; Heise et al., 2003; Keller et al., 2004; Nash et al., 2019; Okoye et al., 2019; Paital and Chainy, 2014). Oxidative challenge due to thermal stress in bivalves and fishes has been further evidenced by the Nrf2-dependent increase of antioxidants such as SOD, CAT, GPx, GR, GST, GSH, and the onset of oxidative damages as lipids peroxidation, loss of DNA integrity, nuclear abnormalities (Feidantsis et al., 2020a; Han et al., 2020 and references therein; Matozzo et al., 2013; Velez et al., 2017). The thermal range of each species plays a fundamental role in determining whether increased temperature elicits the activation of antioxidant responses, possibly hampered by overwhelming heat-mediated protein damage at temperatures close or above the tolerated limit (Madeira et al., 2013, 2016; Tomanek, 2015 and references therein). The proteome of two Mytilus congeners differentially adapted to thermal stress showed diverse responsiveness toward acute heat stress (Tomanek, 2014): the less tolerant species reduced aerobic metabolic pathways to overcome the limited chaperones levels and antioxidant responsiveness compared to the more tolerant species. Despite the common mechanism of regulation through the Nrf2-Keap1 mediated pathway, antioxidant defenses often exhibit asynchronous responses to thermal stress (Han et al., 2020; Klein et al., 2017; Madeira et al., 2013, 2016; Nardi et al., 2017; Nardi et al., 2018b). Several factors contribute to oxidative regulation, including additional protective and/or compensative mechanisms: proteomic studies highlighted depression of arachidonic acid metabolism, decreased abundance of mitochondrial complexes, increased heatshock proteins, upregulation of Toll-like receptor signalling pathway in response to temperature-mediated oxidative stress (Li et al., 2016; Tomanek, 2015 and references therein; Zheng et al., 2019). Tissue-specific effects and seasonalrelated sensitivity toward thermal stress have also been highlighted: in M. galloprovincialis the effects of increased temperature at transcriptional and catalytic levels differed between digestive and respiratory tissues and showed diverse magnitude and thresholds of activation between summer and winter (Feidantsis et al., 2020b; Giuliani et al., 2020; Nardi et al., 2017; 2018b). Only a few studies focused on the role of Nrf2-Keap1 pathway in the antioxidant responsiveness toward thermal stress: $n r f 2$ and antioxidant genes transcription was not altered in Trematomus bernacchii (Boulenger, 1902) adults after 14 days acclimation to higher temperature (Giuliani et al., 2021) and a correlation between thermal stress and $n r f 2$ transcription was not evidenced during any stage of development in embryos of G. morhua (Skjærven et al., 2013). Mechanistic 
studies are thus still needed to unravel the main actors and regulators of cellular responsiveness toward thermal stress and transfer this knowledge to whole organisms physiology.

Ocean acidification is another well recognized challenge (Pörtner, 2008; Tomanek, 2014) which, beside the effects on shell formation-dissolution in marine calcifiers, can affect several biological processes of cellular homeostasis (Tomanek, 2014): onset of cellular hypercapnia and acidosis (decrease of $\mathrm{pH})$ can impact oxygen transport, ion-exchange rates and mitochondrial functioning, leading to increased oxidative stress conditions (Haider et al., 2016; Pörtner, 2008; Tomanek, 2015; Wang et al., 2020b). Three main mechanisms have been hypothesized by Tomanek et al. (2011) to explain acidification-mediated pro-oxidant challenge in marine organisms: i) reactions between cellular $\mathrm{CO}_{2}$ and ONOO- can generate secondary radicals, such as reactive carbonate, oxygen and nitrogen species; ii) in organisms with limited capacity of acid-base regulation, the lowering of intracellular $\mathrm{pH}$ will negatively affect the mitochondrial electron transport chain, resulting in increased electron slip and ROS production; iii) altered intracellular $\mathrm{pH}$ may also facilitate the release of chelated trace metals, like iron and copper which catalyse Fenton reaction and hydroxyl radical production. Experimental studies highlighted increased ROS production under hypercapnic stress (Haider et al., 2016; Wang et al., 2020b), and pro-oxidant effects have been confirmed by several laboratory and field conditions with down- or up-regulation of antioxidant defenses at transcriptional, proteomic and functional level (Cao et al., 2018; de Marchi et al., 2019; Matoo et al., 2013; Munari et al., 2018; Nardi et al., 2018a; Ricevuto et al., 2015; Tomanek et al., 2011). Similarly to what is described for temperaturemediated oxidative pressure, the responsiveness of antioxidant defenses toward reduced-pH/high- $\mathrm{CO}_{2}$ is highly influenced by other factors, including species-specific sensitivity and onset of compensation mechanisms, at least within a limited range of acidification: early increase of ROS in Crassostrea gigas (Thunberg, 1793) exposed to reduced $\mathrm{pH}$ were counteracted in long-term exposure by physiological adjustments supported by the up-regulation of calcium binding proteins and calmodulins (Wang et al., 2020b). Also in M. galloprovincialis long-term exposure to acidification determined up-regulation of genes related to calcium homeostasis, calmodulins and calcium signalling pathways, causing a lower efficiency of antioxidant enzymes and accumulation of lipid peroxidation products (Mezzelani et al., 2021). Changes of acid-base balance in Hyas araneus (Linnaeus, 1758) were coupled with higher metabolism, increase of antioxidant defenses, and more pronounced responsiveness toward moderate rather than high hypercapnia (Harms et al., 2014); the explanation for these shifts was hypothesized to support indirect oxidative pressure due to high $\mathrm{CO}_{2}$, causing energy imbalance and speciesspecific limits of stress tolerance. As already described for thermal stress, sensitivity toward high- $\mathrm{CO}_{2} /$ reduced-pH was demonstrated to vary between investigated tissues and seasons, with non-synchronous effects at transcriptional and catalytic levels (Giuliani et al., 2020; Nardi et al., 2017, 2018b). Antioxidant defenses regulation mechanisms in response to $\mathrm{CO}_{2}$-mediated oxidative stress still need to be fully elucidated and integrated within a physiological perspective of whole organism fitness.

In this context, since ocean warming and acidification are concomitant changes driven by the same cause, the respective interactions and influence on biological processes are of outmost relevance to understand the implications for organisms health. Overall, it has been extensively suggested that the reduction of seawater $\mathrm{pH}$ could narrow the thermal window of organisms reducing their capability to cope with thermal stress, especially in lower marine invertebrates that lack acid-base regulation systems (Pörtner et al., 2017; Pörtner, 2008): thus the onset of oxidative disturbance due to thermal stress could be disclosed earlier. Despite this general assumption, meta-analysis studies on the effects of interactions between temperature and $\mathrm{pH}$ and on the nature of these interactions, revealed that the interplay between thermal and $\mathrm{pH}$ stress is rather than linear and easily depictable, but constrained by physiological aspects regarding tested life-stages and considered taxas (Kroeker et al., 2013; Lefevre, 2016; Przeslawski et al., 2015). Nonetheless, previous studies from our laboratory suggested that the tolerance of marine organisms to concomitant acidification and warming may be subjected to either additive or antagonistic effects of the two stressors, depending on the level of biological organization considered and on the physiological function of the analysed organ (Giuliani et al., 2021; Nardi et al., 2017; 2018a,b; Benedetti et al., 2016). As a corollary, as already demanded for single stressors, mechanistic investigations of the interactive effects of ocean warming and acidification on oxidative pressure and antioxidant responsiveness would deeply increase our knowledge and would be very relevant in the context of finding a unifying principle.

\section{Combined Oxidative Challenge from Emerging Multiple Stressors}

Challenges for marine organisms typically occur and act in a multi-stressors context which may result in a plethora of unexplored additive, synergistic or antagonistic effects (Horton and Barnes, 2020). From a biological and environmentally realistic perspective, an even limited disturbance directly exerted by a single stressor may indirectly alter the susceptibility toward a secondary stressor (Kroeker et al., 2017). In this respect, effects of APIs have been frequently modulated in marine organisms under projected ocean changes scenarios (among others Freitas et al., 2016, 2019; Almeida et al., 2018, 2021; Munari et al., 2018; Mezzelani et al., 2021). Lipid peroxidation due to DIC-exposure was enhanced in mussels M. galloprovincialis exposed at higher temperature despite the activation of antioxidant defenses (Freitas et al., 2019), while this damage was not observed after the induction of antioxidant enzymes in $R$. philippinarum co-exposed to $\mathrm{CBZ}$ and temperature stress (Almeida et al., 2021). On the other hand, CBZ and reduced $\mathrm{pH}$ inhibited CAT activity and interactively increased lipid peroxidation in S. plana, along with negative effects on electron transport activity (Freitas et al., 2016). Under a similar exposure scenario, a synergistic increment of lipofuscin was observed in M. galloprovincialis 
(Mezzelani et al., 2021), in which, despite the lack of antioxidants variations, transcriptomic analyses revealed a conspicuous modulation of several pathways possibly contributing or related to oxidative stress (i.e., ATP generation, energy derivation by oxidation of organic compounds, apoptotic processes and calcium-mediated signalling). Changes in water $\mathrm{pH}$ and/or temperature have also the potential to influence the impact of MPs on organisms, modifying both the intrinsic toxicity of polymers and the bioavailability of chemicals adsorbed on MPs, like pharmaceuticals (Horton and Barnes, 2020; Menéndez-Pedriza and Jaumot, 2020). Interactions between MPs, temperature/pH and APIs were mostly investigated in freshwater organisms (Jaikumar et al., 2018; Kratina et al., 2019; Weber et al., 2020; Guilhermino et al., 2018; Zhang et al., 2019; Schmieg et al., 2020), while little is known for marine species concerning the combined modulation of oxidative pathways.

The effects of PE-MPs on the redox homeostasis of the marine fish Pomatoschistus microps (Kroyer, 1838) were influenced by temperature elevation, with a significant reduction of GST activity and slight effects on lipid peroxidation under temperature increase from $20^{\circ} \mathrm{C}$ to $25^{\circ} \mathrm{C}$ (Ferreira et al., 2016; Fonte et al., 2016). Limited interactive effects of PS-MPs and acidification were reported on antioxidant enzymes of Mytilus coruscus (Gould, 1861) by Wang et al. (2020c), while PET-MPs and acidification comodulated antioxidant enzymes and lipid peroxidation in M. galloprovincialis (Provenza et al., 2020). Interactions between microplastics and pharmaceuticals have been mainly investigated on the sorption/desorption processes under various environmental conditions (Atugoda et al., 2021; Vieira et al., 2021), whereas the possible role of MPs on APIs bioaccumulation, metabolization, and toxicity in marine organisms is poorly explored (Santos et al., 2021). The impact of MPs-antidepressant co-exposure on the blood clam T. granosa, revealed a synergistic effect of sertaline and $30 \mu \mathrm{m}$ PE-microbeads on haemocytes ROS production and lipid peroxidation (Shi et al., 2020). The presence of MPs may facilitate the internalisation of APIs through the "Trojan horse" effect, leading to aggravated toxicity (Zhang and $\mathrm{Xu}, 2020)$. The interactive effect on oxidative stress in T. granosa was further exacerbated by nanoscale $500 \mathrm{~nm}$ PE-beads with a synergistic immuno-toxic effect, highlighting a size-dependent interaction between plastic and sertaline (Shi et al., 2020). Similarly, M. galloprovincialis treated with PS-NPs in combination to the anticonvulsant CBZ revealed synergistic effects on biomarkers of neurotoxicity, carbohydrate metabolism, immune responses and DNA damage, and a slight impairment of oxidative metabolism (total oxidant status, total antioxidant capacity and levels of peroxidation products) (Brandts et al., 2018). The increased toxicity of NPs-APIs compared to MPs-APIs may also arise from a higher amount of pollutants carried and delivered into the organisms due to the larger specific surface area of NPs compared to MPs (Brandts et al., 2018; Shi et al., 2019). Ultimately, short-term exposure of $P$. microps juveniles to PE-microspheres, antibiotic cefalexine and temperature-stress revealed significant interactions on redox homeostasis, as highlighted by the onset of lipid peroxidation (Fonte et al., 2016).
Since oxidative balance can be altered by emerging stressors, acting either alone or in combination, a relevant challenge for marine ecotoxicology is to clarify mechanistic pathways of interaction behind such functional effects, to predict and prevent adverse outcomes affecting higher levels of biological organization.

Author Contribution: Maura Benedetti designed the original idea and wrote the original draft; Maria Elisa Giuliani, Marica Mezzelani, Alessandro Nardi and Lucia Pittura contributed to the bibliographic search and in the original draft writing. Stefania Gorbi and Francesco Regoli edited and reviewed the final version of the manuscript. All authors have approved the final version of the manuscript.

Funding Statement: The authors received no specific funding for this study.

Conflicts of Interest: The authors declare that they have no conflicts of interest to report regarding the present study.

\section{References}

Abele D, Heise K, Pörtner HO, Puntarulo S (2002). Temperaturedependence of mitochondrial function and production of reactive oxygen species in the intertidal mud clam Mya arenaria. Journal of Experimental Biology 205: 1831-1841.

Alimba CG, Faggio C (2019). Microplastics in the marine environment: Current trends in environmental pollution and mechanisms of toxicological profile. Environmental Toxicology and Pharmacology 68: 61-74. DOI 10.1016/j. etap.2019.03.001.

Almeida Â, Freitas R, Calisto V, Esteves VI, Schneider RJ et al. (2018). Effects of carbamazepine and cetirizine under an ocean acidification scenario on the biochemical and transcriptome responses of the clam Ruditapes philippinarum. Environmental Pollution 235: 857-868. DOI 10.1016/j. envpol.2017.12.121.

Almeida A, Solé M, Soares A, Freitas R (2020). Anti-inflammatory drugs in the marine environment: Bioconcentration, metabolism and sub-lethal effects in marine bivalves. Environmental Pollutants 263: 114442. DOI 10.1016/j. envpol.2020.114442.

Almeida Â, Calisto V, Esteves VI, Schneider RJ, Figueira E et al. (2021). Can ocean warming alter sub-lethal effects of antiepileptic and antihistaminic pharmaceuticals in marine bivalves? Aquatic Toxicology 230: 105673. DOI 10.1016/j. aquatox.2020.105673.

Atugoda T, Vithanage M, Wijesekara H, Bolan N, Sarmah AK, Bank MS, Yong S, Ok YS (2021). Interactions between microplastics, pharmaceuticals and personal care products: Implications for vector transport. Environment International 149: 106367. DOI 10.1016/j. envint.2020.106367.

Bebianno MJ, Gonzalez-Rey M (2015). Ecotoxicological risk of personal care products and pharmaceuticals in claude Amiard-Triquet, Jean-Claude Amiard and Catherine Mouneyrac, Aquatic Ecotoxicology. Advancing Tools for Dealing with Emerging Risks 16: 383-416.

Benedetti M, Giuliani ME, Regoli F (2015). Oxidative metabolism of chemical pollutants in marine organisms: Molecular and biochemical biomarkers in environmental toxicology. 
Annals of the New York Academy of Sciences 1340: 8-19. DOI 10.1111/nyas.12698.

Benedetti M, Lanzoni I, Nardi A, d'Errico G, Di Carlo M, Fattorini D, Nigro M, Regoli F (2016). Oxidative responsiveness to multiple stressors in the key Antarctic species, Adamussium colbecki: Interactions between temperature, acidification and cadmium exposure. Marine Environmental Research 121: 20-30. DOI 10.1016/j.marenvres.2016.03.011.

Bessa F, Frias J, Kögel T, Lusher A, Andrade JM et al. (2019). Harmonized protocol for monitoring microplastics in biota. JPI-Oceans BASEMAN Project.

Brandts I, Teles M, Gonçalves AP, Barreto A, Franco-Martinez L, Tvarijonaviciute A, Martins MA, Soares AMVM, Tort L, Oliveira M (2018). Effects of nanoplastics on Mytilus galloprovincialis after individual and combined exposure with carbamazepine. Science of the Total Environment 643: 775-784. DOI 10.1016/j.scitotenv.2018.06.257.

Burkina V, Zlabek V, Zamaratskaia G (2015). Effects of pharmaceuticals present in aquatic environment on Phase I metabolism in fish. Environmental Toxicology and Pharmacology 40: 430-444. DOI 10.1016/j.etap.2015.07.016.

Cao R, Liu Y, Wang Q, Dong Z, Yang D, Liu H, Ran W, Qu Y, Zhao J (2018). Seawater acidification aggravated cadmium toxicity in the oyster Crassostrea gigas: Metal bioaccumulation, subcellular distribution and multiple physiological responses. Science of the Total Environment 642: 809-823. DOI 10.1016/j.scitotenv.2018.06.126.

Capó X, Company JJ, Alomar C, Compa M, Sureda A et al. (2021). Long-term exposure to virgin and seawater exposed microplastic enriched-diet causes liver oxidative stress and inflammation in gilthead seabream Sparus aurata, Linnaeus 1758. Science of the Total Environment 767: 144976. DOI 10.1016/j.scitotenv.2021.144976.

Choi JS, Hong SH, Park JW (2020). Evaluation of microplastic toxicity in accordance with different sizes and exposure times in the marine copepod Tigriopus japonicus. Marine environmental research 153: 104838. DOI 10.1016/j.marenvres.2019.104838.

Cole M, Lindeque P, Halsband C, Galloway TS (2011). Microplastics as contaminants in the marine environment: A review. Marine pollution bulletin 62: 2588-2597. DOI 2588-2597. doi 10.1016/j.marpolbul.2011.09.025.

Gonçalves JM, Bebianno MJ (2021). Nanoplastics impact on marine biota: A review. Environmental Pollution 273: 116426. DOI 10.1016/j.envpol.2021.116426.

de Marchi L, Pretti C, Chiellini F, Morelli A, Neto V, Soares AMVM, Figueira E, Freitas R (2019). Impacts of ocean acidification on carboxylated carbon nanotube effects induced in the clam species Ruditapes philippinarum. Environmental Science and Pollution Research 26: 20742-20752. DOI 10.1007/ s11356-019-05306-8.

Elizalde-Velázquez A, Subbiah S, Anderson TA, Green MJ, Zhao X, Canas-Carrell JE (2020). Sorption of three common nonsteroidal anti-inflammatory drugs (NSAIDs) to microplastics. Science of the Total Environment 715: 136974. DOI 10.1016/j.scitotenv.2020.136974.

Espinosa C, García Beltrán JM, Esteban MA, Cuesta A (2018). In vitro effects of virgin microplastics on fish head-kidney leucocyte activities. Environmental Pollution 235: 30-38. DOI 10.1016/j.envpol.2017.12.054.

Espinosa-Diez C, Miguel V, Mennerich D, Kietzmann T, SánchezPérez P et al. (2015). Antioxidant responses and cellular adjustments to oxidative stress. Redox Biology 6: 183-197. DOI 10.1016/j.redox.2015.07.008.
Feidantsis K, Georgoulis I, Zachariou A, Campaz B, Christoforou M, Pörtner HO, Michaelidis B (2020a). Energetic, antioxidant, inflammatory and cell death responses in the red muscle of thermally stressed Sparus aurata. Journal of Comparative Physiology B: Biochemical, Systemic, and Environmental Physiology 190: 403-418. DOI 10.1007/s00360-020-01278-1.

Feidantsis K, Giantsis IA, Vratsistas A, Makri S, Pappa AZ et al. (2020b). Correlation between intermediary metabolism, Hsp gene expression, and oxidative stress-related proteins in long-term thermal-stressed Mytilus galloprovincialis. American Journal of Physiology-Regulatory Integrative and Comparative Physiology 319: R264-R281. DOI 10.1152/ ajpregu.00066.2020.

Ferreira P, Fonte E, Soares ME, Carvalho F, Guilhermino L (2016). Effects of multi-stressors on juveniles of the marine fish Pomatoschistus microps: Gold nanoparticles, microplastics and temperature. Aquatic Toxicology 170: 89-103. DOI 10.1016/j.aquatox.2015.11.011.

Fonte E, Ferreira P, Guilhermino L (2016). Temperature rise and microplastics interact with the toxicity of the antibiotic cefalexin to juveniles of the common goby (Pomatoschistus microps): Post-exposure predatory behaviour, acetylcholinesterase activity and lipid peroxidation. Aquatic Toxicology 180: 173-185. DOI 10.1016/j.aquatox.2016.09.015.

Franzellitti S, Buratti S, Capolupo M, Du B, Haddad SP, Chambliss CK, Brooks BW, Fabbri E (2014). An exploratory investigation of various modes of action and potential adverse outcomes of fluoxetine in marine mussels. Aquatic Toxicology 151: 14-26. DOI 10.1016/j.aquatox.2013.11.016.

Freitas R, Almeida A, Calisto V, Velez C, Moreira A et al. (2016). The impacts of pharmaceutical drugs under ocean acidification: New data on single and combined long-term effects of carbamazepine on Scrobicularia plana. Science of the Total Environment 541: 977-985. DOI 10.1016/j. scitotenv.2015.09.138.

Freitas R, Coppola F, Costa S, Pretti C, Intorre L, Meucci V, Soares AMVM, Solé M (2019). The influence of temperature on the effects induced by Triclosan and Diclofenac in mussels. Science of the Total Environment 663: 992-999. DOI 10.1016/j.scitotenv.2019.01.189.

Ghosh R, Alajbegovic A, Gomes AV (2015). NSAIDs and cardiovascular diseases: Role of reactive oxygen species. Oxidative Medicine \& Cellular Longevity 25: 536962. DOI $10.1155 / 2015 / 536962$.

Giuliani ME, Filippini G, Nardi A (2020). Season specific influence of projected ocean changes on the response to cadmium of stress-related genes in Mytilus galloprovincialis. Marine Environmental Research 162: 105091. DOI 10.1016/j. marenvres.2020.105091.

Giuliani ME, Nardi A, Di Carlo M, Benedetti M, Regoli F (2021). Transcriptional and catalytic responsiveness of the Antarctic fish Trematomus bernacchii antioxidant system toward multiple stressors. Antioxidants 10: 410. DOI 10.3390/antiox10030410.

Guilhermino L, Vieira LR, Ribeiro D, Tavares AS, Cardoso V, Alves A, Almeida JM (2018). Uptake and effects of the antimicrobial florfenicol, microplastics and their mixtures on freshwater exotic invasive bivalve Corbicula fluminea. Science of the Total Environment 622-623: 1131-1142. DOI 10.1016/j.scitotenv.2017.12.020.

Haider F, Falfushynska H, Ivanina AV, Sokolova IM (2016). Effects of $\mathrm{pH}$ and bicarbonate on mitochondrial functions of marine bivalves. Comparative Biochemistry and Physiology 
-Part A: Molecular and Integrative Physiology 198: 41-50. DOI 10.1016/j.cbpa.2016.03.021.

Halliwell B, Gutteridge MC (2015). Free radicals in Biology and Medicine. Oxford Scholarship Online. DOI 10.1093/acprof: oso/9780198717478.001.0001.

Hampel M, Blasco J, Babbucci M, Ferraresso S, Bargelloni L, Milan M (2017). Transcriptome analysis of the brain of the sea bream (Sparus aurata) after exposure to human pharmaceuticals at realistic environmental concentrations. Marine Environmental Research 129: 36-45. DOI 10.1016/j.marenvres.2017.04.012.

Han J, Lee JS, Park JC, Hagiwara A, Lee KW, Lee JS (2020). Effects of temperature changes on life parameters, oxidative stress, and antioxidant defense system in the monogonont marine rotifer Brachionus plicatilis. Marine Pollution Bulletin 155: 111062. DOI 10.1016/j.marpolbul.2020.111062.

Hariharan G, Purvaja R, Anandavelu I, Robin RS, Ramesh R (2021). Accumulation and ecotoxicological risk of weathered polyethylene (wPE) microplastics on green mussel (Perna viridis). Ecotoxicology and Environmental Safety 208: 111765. DOI 10.1016/j.ecoenv.2020.111765.

Harms L, Frickenhaus S, Schiffer M, Mark FC, Storch D, Held C, Pörtner HO, Lucassen M (2014). Gene expression profiling in gills of the great spider crab Hyas araneus in response to ocean acidification and warming. BMC Genomics 15: 789. DOI 10.1186/1471-2164-15-789.

Heise K, Puntarulo S, Pörtner HO, Abele D (2003). Production of reactive oxygen species by isolated mitochondria of the Antarctic bivalve Laternula elliptica (King and Broderip) under heat stress. Comparative Biochemistry and Physiology-C Toxicology and Pharmacology 134: 79-90. DOI 10.1016/s1532-0456(02)00212-0.

Horton AA, Barnes DK (2020). Microplastic pollution in a rapidly changing world: Implications for remote and vulnerable marine ecosystems. Science of the Total Environment 738: 140349. DOI 10.1016/j.scitotenv.2020.140349.

Hu M, Palić D (2020). Micro-and nano-plastics activation of oxidative and inflammatory adverse outcome pathways. Redox Biology 37: 101620. DOI 10.1016/j.redox.2020.101620.

IPCC (2013). Climate change 2013: The physical science basis. Contribution of Working Group I to the Fifth Assessment Report of the Intergovernmental Panel on Climate Change. Cambridge, UK and New York, NY, USA: Cambridge University Press.

IQVIA (2019). The global use of medicine in 2019 and outlook to 2023. Forecasts and Areas to Watch. Institute for Human Data Science.

Jaikumar G, Baas J, Brun NR, Vijver MG, Bosker T (2018). Acute sensitivity of three Cladoceran species to different types of microplastics in combination with thermal stress. Environmental Pollution 239: 733-740. DOI 10.1016/j. envpol.2018.04.069.

Jeong CB, Kang HM, Lee MC, Kim DH, Han J et al. (2017). Adverse effects of microplastics and oxidative stress-induced MAPK/ Nrf2 pathway-mediated defense mechanisms in the marine copepod Paracyclopina nana. Scientific Reports 7: 41323. DOI 10.1038/srep41323.

Jeong CB, Won EJ, Kang HM, Lee MC, Hwang DS, Hwang UK, Zhou B, Souissi S, Lee SJ, Lee JS (2016). Microplastic sizedependent toxicity, oxidative stress induction, and p-JNK and p-p38 activation in the monogonont rotifer (Brachionus koreanus). Environmental Science \& Technology 50: 8849-8857. DOI 10.1021/acs.est.6b01441.
Kang HM, Byeon E, Jeong H, Kim MS, Chen Q, Lee JS (2021). Different effects of nano-and microplastics on oxidative status and gut microbiota in the marine medaka Oryzias melastigma. Journal of Hazardous Materials 405: 124207. DOI 10.1016/j.jhazmat.2020.124207.

Keller M, Sommer AM, Pörtner HO, Abele D (2004). Seasonality of energetic functioning and production of reactive oxygen species by lugworm (Arenicola marina) mitochondria exposed to acute temperature changes. Journal of Experimental Biology 207: 2529-2538. DOI 10.1242/jeb.01050.

Kim JH, Yu YB, Choi JH (2021). Toxic effects on bioaccumulation, hematological parameters, oxidative stress, immune responses and neurotoxicity in fish exposed to microplastics: A review. Journal of Hazardous Materials 413: 125423. DOI 10.1016/j.jhazmat.2021.125423.

Klein RD, Borges VD, Rosa CE, Colares EP, Robaldo RB, Martinez PE, Bianchini A (2017). Effects of increasing temperature on antioxidant defense system and oxidative stress parameters in the Antarctic fish Notothenia coriiceps and Notothenia rossii. Journal of Thermal Biology 68: 110-118. DOI 10.21203/rs.3.rs-160120/v.

Kovalakova P, Cizmas L, Donald TJM, Marsalek B, Feng M, Sharma VK (2020). Occurrence and toxicity of antibiotics in the aquatic environment: A review. Chemosphere 251: 126351. DOI 10.1016/j.chemosphere.2020.126351.

Kratina P, Watts TJ, Green DS, Kordas RL, O'Gorman EJ (2019). Interactive effects of warming and microplastics on metabolism but not feeding rates of a key freshwater detritivore. Environmental Pollution 255: 113259. DOI 10.1016/j.envpol.2019.113259.

Kroeker KJ, Kordas RL, Harley CDG (2017). Embracing interactions in ocean acidification research: Confronting multiple stressor scenarios and context dependence. Biology Letters 13: 20160802. DOI 10.1098/rsbl.2016.0802.

Kroeker KJ, Kordas RL, Crim R, Hendriks IE, Ramajo L, Singh GS, Duarte CM, Gattuso JP (2013). Impacts of ocean acidification on marine organisms: Quantifying sensitivities and interaction with warming. Global Change Biology 19: 1884-1896. DOI 10.1111/gcb.12179.

Lefevre S (2016). Are global warming and ocean acidification conspiring against marine ectotherms? A meta-analysis of the respiratory effects of elevated temperature, high $\mathrm{CO}_{2}$ and their interaction. Conservation Physiology 4: cow009. DOI 10.1093/conphys/cow009.

Li S, Liu C, Huang J, Liu Y, Zhang S et al. (2016). Transcriptome and biomineralization responses of the pearl oyster Pinctada fucata to elevated $\mathrm{CO}_{2}$ and temperature. Scientific Reports 6: 18943 . DOI 10.1038/srep18943.

Lusher A (2015). Microplastics in the marine environment: Distribution, interactions and effects. In: Bergmann $\mathrm{M}$, Gutow L, Klages M (eds.), Marine Anthropogenic Litter. Cham: Springer. DOI 10.1007/978-3-319-16510-3_10.

Madeira D, Narciso L, Cabral HN, Vinagre C, Diniz MS (2013). Influence of temperature in thermal and oxidative stress responses in estuarine fish. Comparative Biochemistry and Physiology-A Molecular and Integrative Physiology 166: 237-243. DOI 10.1016/j.cbpa.2013.06.008.

Madeira D, Vinagre C, Diniz MS (2016). Are fish in hot water? Effects of warming on oxidative stress metabolism in the commercial species Sparus aurata. Ecological Indicators 63: 324-331. DOI 10.1016/j.ecolind.2015.12.008.

Martínez-Morcillo S, Rodríguez-Gil JL, Fernández-Rubio J, Rodríguez-Mozaz S, Míguez-Santiyán MP, Valdes ME, 
Barceló D, Valcárcel Y (2020). Presence of pharmaceutical compounds, levels of biochemical biomarkers in seafood tissues and risk assessment for human health: Results from a case study in North-Western Spain. International Journal of Hygiene Environmental Health 223: 10-21. DOI 10.1016/ j.ijheh.2019.10.011.

Matoo OB, Ivanina AV, Ullstad C, Beniash E, Sokolova MI (2013). Interactive effects of elevated temperature and $\mathrm{CO}_{2}$ levels on metabolism and oxidative stress in two common marine bivalves (Crassostrea virginica and Mercenaria mercenaria). Comparative Biochemistry and Physiology-A Molecular and Integrative Physiology 164: 545-553. DOI 10.1016/j. cbpa.2013.05.016.

Matozzo V, Chinellato A, Munari M, Bressan M, Marin MG (2013). Can the combination of decreased $\mathrm{pH}$ and increased temperature values induce oxidative stress in the clam Chamelea gallina and the mussel Mytilus galloprovincialis? Marine Pollution Bulletin 72: 34-40. DOI 10.1016/j.marpolbul.2013.05.004.

Menéndez-Pedriza A, Jaumot J (2020). Interaction of environmental Pollutants with microplastics: A critical review of sorption factors, bioaccumulation and ecotoxicological effects. Toxics 8: 40. DOI 10.3390/toxics8020040.

Mezzelani M, Fattorini D, Gorbi S, Nigro M, Regoli F (2020). Human pharmaceuticals in marine mussels: Evidence of sneaky hazard along Italian coasts. Marine Environmental Research 162: 105137. DOI 10.1016/j.marenvres.2020.105137.

Mezzelani M, Gorbi S, Regoli F (2018a). Pharmaceuticals in the aquatic environments: Evidence of emerged threat and future challenges for marine organisms. Marine Environmental Research 140: 41-60. DOI 10.1016/j. marenvres.2018.05.001.

Mezzelani M, Gorbi S, Fattorini D, d'Errico G, Consolandi G et al. (2018b). Long-term exposure of Mytilus galloprovincialis to Diclofenac, Ibuprofen and Ketoprofen: insights into bioavailability, biomarkers and transcriptomic changes. Chemosphere 198: 238-248. DOI 10.1016/j. chemosphere.2018.01.148.

Mezzelani M, Nardi A, Bernardini I, Milan M, Peruzza L, d’Errico G, Fattorini D, Gorbi S, Patarnello T, Regoli F (2021). Environmental pharmaceuticals and climate change: The case study of carbamazepine in M. galloprovincialis under ocean acidification scenario. Environmental International 146: 106269. DOI 10.1016/j.envint.2020.106269.

Moreno-González R, Rodríguez-Mozaz S, Huerta B, Barceló D, León VM (2016). Do pharmaceuticals bioaccumulate in marine molluscs and fish from a coastal lagoon? Environmental Research 146: 282-298. DOI 10.1016/j.envres.2016.01.001.

Munari M, Marin MG, Matozzo V (2014). Effects of the antidepressant fluoxetine on the immune parameters and acetylcholinesterase activity of the clam Venerupis philippinarum. Marine Environmental Research 94: 32-37. DOI 10.1016/j.marenvres.2013.11.007.

Munari M, Matozzo V, Gagné F, Chemello G, Riedl V, Finos L, Pastore P, Badocco D, Marin MG (2018). Does exposure to reduced $\mathrm{pH}$ and diclofenac induce oxidative stress in marine bivalves? A comparative study with the mussel Mytilus galloprovincialis and the clam Ruditapes philippinarum. Environmental Pollution 240: 925-937. DOI 10.1016/j.envpol.2018.05.005.

Nardi A, Benedetti M, Fattorini D, Regoli F (2018a). Oxidative and interactive challenge of cadmium and ocean acidification on the smooth scallop Flexopecten glaber. Aquatic Toxicology 196: 53-60. DOI 10.1016/j.aquatox.2018.01.008.
Nardi A, Benedetti M, d’Errico G, Fattorini D, Regoli F (2018b). Effects of ocean warming and acidification on accumulation and cellular responsiveness to cadmium in mussels Mytilus galloprovincialis: Importance of the seasonal status. Aquatic Toxicology 204: 171-179. DOI 10.1016/j.aquatox.2018.09.009.

Nardi A, Mincarelli LF, Benedetti M, Fattorini D, d'Errico G, Regoli F (2017). Indirect effects of climate changes on cadmium bioavailability and biological effects in the Mediterranean mussel Mytilus galloprovincialis. Chemosphere 169: 493502. DOI 10.1016/j.chemosphere.2016.11.093.

Nash S, Johnstone J, Rahman MS (2019). Elevated temperature attenuates ovarian functions and induces apoptosis and oxidative stress in the American oyster, Crassostrea virginica: Potential mechanisms and signaling pathways. Cell Stress and Chaperones 24: 957-967. DOI 10.1007/s12192-01901023-w.

Ojemaye CY, Petrik L (2019). Occurrences, levels and risk assessment studies of emerging pollutants (pharmaceuticals, perfluoroalkyl and endocrine disrupting compounds) in fish samples from Kalk Bay harbour, South Africa. Environmental Pollution 252: 562-572. DOI 10.1016/j.envpol.2019.05.091.

Okoye CN, MacDonald-Jay N, Kamunde C (2019). Effects of bioenergetics, temperature and cadmium on liver mitochondria reactive oxygen species production and consumption. Aquatic Toxicology 214: 105264. DOI 10.1016/j.aquatox.2019.105264.

Paital B, Chainy GBN (2014). Effects of temperature on complexes I and II mediated respiration, ROS generation and oxidative stress status in isolated gill mitochondria of the mud crab Scylla serrata. Journal of Thermal Biology 41: 104-111. DOI 10.1016/j.jtherbio.2014.02.013.

Parolini M, Ferrario C, De Felice B, Gazzotti S, Bonasoro F et al. (2020). Interactive effects between sinking polyethylene terephthalate (PET) microplastics deriving from water bottles and a benthic grazer. Journal of Hazardous Materials 398: 122848. DOI 10.1016/j.jhazmat.2020.122848.

Paul-Pont I, Tallec K, Gonzalez-Fernandez C, Lambert C, Vincent D et al. (2018). Constraints and priorities for conducting experimental exposures of marine organisms to microplastics. Frontiers in Marine Science 5: 252. DOI 10.3389/fmars.2018.00252.

Paul-Pont I, Lacroix C, Fernández CG, Hégaret H, Lambert C et al. (2016). Exposure of marine mussels Mytilus spp. to polystyrene microplastics: Toxicity and influence on fluoranthene bioaccumulation. Environmental Pollution 216: 724-737. DOI 10.1016/j.envpol.2016.06.039.

Pittura L, Avio CG, Giuliani ME, d'Errico G, Keiter SH, Cormier B, Gorbi S, Regoli F (2018). Microplastics as vehicles of environmental PAHs to marine organisms: Combined chemical and physical hazards to the Mediterranean mussels, Mytilus galloprovincialis. Frontiers in Marine Science 5: 103. DOI 10.3389/fmars.2018.00103.

Pörtner HO (2008). Ecosystem effects of ocean acidification in times of ocean warming: A physiologist's view. Marine Ecology Progress Series 373: 203-217. DOI 10.3354/meps07768.

Pörtner HO, Hardewig I, Peck LS (1999). Mitochondrial function and critical temperature in the Antarctic bivalve, Laternula elliptica. Comparative Biochemistry and Physiology-A Molecular and Integrative Physiology 124: 179-189. DOI 10.1016/S1095-6433(99)00105-1.

Pörtner HO, Bock C, Mark FC (2017). Oxygen- \& capacity-limited thermal tolerance: Bridging ecology \& physiology. Journal of Experimental Biology 220: 2685-2696. DOI 10.1242/ jeb. 134585 . 
Provenza F, Piccardo M, Terlizzi A, Renzi M (2020). Exposure to petmade microplastics: Particle size and $\mathrm{pH}$ effects on biomolecular responses in mussels. Marine Pollution Bulletin 156: 111228. DOI 10.1016/j.marpolbul.2020.111228.

Przeslawski R, Byrne M, Mellin C (2015). A review and meta-analysis of the effects of multiple abiotic stressors on marine embryos and larvae. Global Change Biology 21: 2122-2140. DOI $10.1111 / \mathrm{gcb} .12833$.

Regoli F, Giuliani ME (2014). Oxidative pathways of chemical toxicity and oxidative stress biomarkers in marine organisms. Marine Environmental Research 93: 106-117. DOI 10.1016/j.marenvres.2013.07.006.

Ricevuto E, Benedetti M, Regoli F, Spicer JI, Gambi MC (2015). Antioxidant capacity of polychaetes occurring at a natural $\mathrm{CO}_{2}$ vent system: Results of an in situ reciprocal transplant experiment. Marine Environmental Research 112: 44-51. DOI 10.1016/j.marenvres.2015.09.005.

Rodrigues S, Antunes SC, Correia AT, Golovko O, Žlábek V, Nunes B (2019). Assessment of toxic effects of the antibiotic erythromycin on the marine fish gilthead seabream (Sparus aurata L.) by a multi-biomarker approach. Chemosphere 216: 234-247. DOI 10.1016/j.chemosphere.2018.10.124.

Ruiz CE, Manuguerra S, Curcuraci E, Santulli A, Messina CM (2020). Carbamazepine, cadmium chloride and polybrominated diphenyl ether-47, synergistically modulate the expression of antioxidants and cell cycle biomarkers, in the marine fish cell line SAF-1. Marine Environmental Research 154: 104844. DOI 10.1016/j.marenvres.2019.104844.

Sachdev S, Ansari SA, Ansari MI, Fujita M, Hasanuzzaman M (2021). Abiotic stress and reactive oxygen species: Generation, signaling, and defense mechanisms. Antioxidants 10: 277. DOI 10.3390/antiox10020277.

Santos LHMLM, Rodríguez-Mozaz S, Barceló D (2021). Microplastics as vectors of pharmaceuticals in aquatic organisms-An overview of their environmental implications. Case Studies in Chemical and Environmental Engineering 3: 100079. DOI 10.1002/etc.3461.

Schmieg H, Burmester JKY, Krais S, Ruhl AS, Tisler S, Zwiener C, Köhler HR, Triebskorn R (2020). Interacting effects of polystyrene microplastics and the antidepressant amitriptyline on early life stages of Brown trout (Salmo trutta f. fario). Water 12: 2361. DOI 10.3390/w12092361.

Shi W, Han Y, Guan X, Rong J, Su W, Zha S, Tang Y, Du X, Liu G (2019). Fluoxetine suppresses the immune responses of blood clams by reducing haemocyte viability, disturbing signal transduction and imposing physiological stress. Science of the Total Environment 683: 681-689. DOI 10.1016/j.scitotenv.2019.05.308.

Shi W, Han Y, Sun S, Tang Y, Zhou W, Du X, Liu G (2020). Immunotoxicities of microplastics and sertraline, alone and in combination, to a bivalve species: Size-dependent interaction and potential toxication mechanism. Journal of Hazardous Materials 396: 122603. DOI 10.1016/j. jhazmat.2020.122603.

Sıkdokur E, Belivermiş M, Sezer N, Pekmez M, Bulan ÖK et al. (2020). Effects of microplastics and mercury on manila clam Ruditapes philippinarum: Feeding rate, immunomodulation, histopathology and oxidative stress. Environmental Pollution 262: 114247. DOI 10.1016/j. envpol.2020.114247.

Skjærven KH, Penglase S, Olsvik PA, Hamre K (2013). Redox regulation in Atlantic cod (Gadus morhua) embryos developing under normal and heat-stressed conditions. Free
Radical Biology and Medicine 57: 29-38. DOI 10.1016/j. freeradbiomed.2012.11.022.

Sorensen RM, Jovanović B (2021). From nanoplastic to microplastic: A bibliometric analysis on the presence of plastic particles in the environment. Marine Pollution Bulletin 163: 111926. DOI 10.1016/j.marpolbul.2020.111926.

Suman TY, Jia PP, Li WG, Junaid M, Xin GY, Wang Y, Pei DS (2020). Acute and chronic effects of polystyrene microplastics on brine shrimp: First evidence highlighting the molecular mechanism through transcriptome analysis. Journal of Hazardous Materials 400: 123220. DOI 10.1016/j.jhazmat.2020.123220.

Tang J, Ni X, Zhou Z, Wang L, Lin S (2018). Acute microplastic exposure raises stress response and suppresses detoxification and immune capacities in the scleractinian coral Pocillopora damicornis. Environmental pollution 243: 66-74. DOI 10.1016/j.envpol.2018.08.045.

Tang Y, Rong J, Guan X, Zha S, Shi W, Han Y, Du X, Wu F, Huang W, Liu G (2020). Immunotoxicity of microplastics and two persistent organic pollutants alone or in combination to a bivalve species. Environmental Pollution 258: 113845. DOI 10.1016/j.jhazmat.2020.122603.

Thoral E, Roussel D, Chinopoulos C, Teulier L, Salin K (2021). Low oxygen levels can help to prevent the detrimental effect of acute warming on mitochondrial efficiency in fish. Biology Letters 17: 20200759. DOI 10.1098/rsbl.2020.0759.

Tomanek L (2014). Proteomics to study adaptations in marine organisms to environmental stress. Journal of Proteomics 105: 92-106. DOI 10.1016/j.jprot.2014.04.009.

Tomanek L (2015). Proteomic responses to environmentally induced oxidative stress. Journal of Experimental Biology 218: 18671879. DOI 10.1242/jeb.116475.

Tomanek L, Zuzow MJ, Ivanina AV, Beniash E, Sokolova IM (2011). Proteomic response to elevated $\mathrm{P}_{\mathrm{CO}_{2}}$ level in eastern oysters, Crassostrea virginica: Evidence for oxidative stress. Journal of Experimental Biology 214: 1836-1844. DOI 10.1242/jeb.055475.

Trestrail C, Nugegoda D, Shimeta J (2020). Invertebrate responses to microplastic ingestion: Reviewing the role of the antioxidant system. Science of the Total Environment 734: 138559. DOI 10.1016/j.scitotenv.2020.138559.

UNEP (2016). Marine Plastic Debris and Microplastics-Global Lessons and Research to Inspire Action and Guide Policy Change. Nairobi: United Nations Environment Programme.

Velez C, Figueira E, Soares AMVM, Freitas R (2017). Effects of seawater temperature increase on economically relevant native and introduced clam species. Marine Environmental Research 123: 62-70. DOI 10.1016/j. marenvres.2016.11.010.

Vieira Y, Lima EC, Foletto EL, Dotto GL (2021). Microplastics physicochemical properties, specific adsorption modeling and their interaction with pharmaceuticals and other emerging contaminants. Science of the Total Environment 753: 141981. DOI 10.1016/j.scitotenv.2020.141981.

Wang X, Huang Wei, Shang S, Gu Y, Wu H et al. (2020c). Microplastics impair digestive performance but show little effects on antioxidant activity in mussels under low $\mathrm{pH}$ conditions. Environmental Pollution 258: 113691. DOI 10.1016/j.envpol.2019.113691.

Wang X, Wang M, Wang W, Liu Z, Xu J et al. (2020b). Transcriptional changes of Pacific oyster Crassostrea gigas reveal essential role of calcium signal pathway in response to $\mathrm{CO}_{2}$-driven acidification. Science of the Total Environment 741: 140177. DOI 10.1016/j.scitotenv.2020.140177. 
Wang Y, Wang C, Bao S, Nie X (2020a). Responses of the Nrf2/Keap1 signaling pathway in Mugilogobius abei (M. abei) exposed to environmentally relevant concentration aspirin. Environmental Science and Pollution Research International 27: 15663-15673. DOI 10.1007/s11356-020-07912-3.

Weber A, Jeckel N, Wagner M (2020). Combined effects of polystyrene microplastics and thermal stress on the freshwater mussel Dreissena polymorpha. Science of the Total Environment 718: 137253. DOI 10.1016/j. scitotenv.2020.137253.

Wolecki D, Caban M, Pazdro K, Mulkiewicz E, Stepnowski P, Kumirska J (2019). Simultaneous determination of nonsteroidal anti-inflammatory drugs and natural estrogens in the mussels Mytilus edulis trossulus. Talanta 200: 316-323. DOI 10.1016/j.talanta.2019.03.062.

Yang H, Xiong H, Mi K, Xue W, Wei W, Zhang Y (2020). Toxicity comparison of nano-sized and micron-sized microplastics to Goldfish Carassius auratus Larvae. Journal of Hazardous Materials 388: 122058. DOI 10.1016/j.jhazmat.2020.122058.
Zhang K, Zhao Y, Fent K (2020). Cardiovascular drugs and lipid regulating agents in surface waters at global scale: Occurrence, ecotoxicity and risk assessment. Science of the Total Environment 729: 138770. DOI 10.1016/j.scitotenv.2020.138770.

Zhang M, Xu L (2020). Transport of micro-and nanoplastics in the environment: Trojan-Horse effect for organic contaminants. Critical Reviews in Environmental Science and Technology (in Press). DOI 10.1080/10643389.2020.1845531.

Zhang S, Ding J, Razanajatovo RM, Jiang H, Zou H, Zhu W (2019). Interactive effects of polystyrene microplastics and roxithromycin on bioaccumulation and biochemical status in the freshwater fish red tilapia (Oreochromis niloticus). Science of the Total Environment 648: 1431-1439. DOI 10.1016/j.scitotenv.2018.08.266.

Zheng J, Cao J, Mao Y, Su Y, Wang J (2019). Comparative transcriptome analysis provides comprehensive insights into the heat stress response of Marsupenaeus japonicus. Aquaculture 502: 338-346. DOI 10.1016/j.aquaculture. 2018.11.023. 